\title{
The Energy Cycle Associated to the Pacific Walker Circulation and Its Relationship to ENSO
}

\author{
José Augusto P. Veiga ${ }^{*}$, Alexandre B. Pezza ${ }^{2}$, Tercio Ambrizzi ${ }^{3}$, \\ V. Brahmananda Rao ${ }^{4}$, Sergio H. Franchito ${ }^{4}$, Marcos C. Yoshida ${ }^{4}$ \\ ${ }^{1}$ Institute of Technology, Amazon State University, Manaus, Brazil \\ ${ }^{2}$ School of Earth Sciences, The University of Melbourne, Victoria, Australia \\ ${ }^{3}$ Institute of Astronomy, Geophysics and Atmospheric Sciences, University of São Paulo, São Paulo, Brazil \\ ${ }^{4}$ National Institute for Space Reseach, São José dos Campos, Brazil \\ Email: *veiga.uea@gmail.com
}

Received October 7, 2013; revised October 26, 2013; accepted October 31, 2013

Copyright (C) 2013 José Augusto P. Veiga et al. This is an open access article distributed under the Creative Commons Attribution License, which permits unrestricted use, distribution, and reproduction in any medium, provided the original work is properly cited.

\begin{abstract}
In this paper we study the Lorenz energy cycle of the Walker circulation associated with ENSO. The robust formulation of the energetics allows drawing a clear picture of the global energy and conversion terms associated with the three dimensional domains appropriate to qualify the large scale transfers that influence, and are influenced by, the anomalies during ENSO. A clear picture has emerged in that El Niño and La Niña years have approximately opposite anomalous energy fluxes, regardless of a non-linear response identified in the potential energy fields (zonal and eddy). During El Niños the tropical atmosphere is characterized by an increase of zonal available potential energy, decrease of eddy available potential energy and decrease of kinetic energy fields. This results in weaker upper level jets and a slowingdown of the overall Walker cell. During La Niñas reversed conditions are triggered, with an acceleration of the Walker cell as observed from the positive anomalous kinetic energy. The potential energy in the Walker circulation domain during the cold phase is also reduced. An equally opposite behavior is also experienced by the energy conversion terms according to the ENSO phase. The behavior of anomalous energetics seems to be triggered at about the same time when ENSO starts to manifest for both the positive and negative phases, suggesting a coupled mechanism in which atmospheric and oceanic anomalies interact and feed back onto each other.
\end{abstract}

Keywords: Walker Circulation; Energetics; El Niño; La Niña; ENSO

\section{Introduction}

The Walker circulation (WC) can be defined as a longitudinal overturning circulation that is closely tied to the east-west SST gradient along the equatorial Pacific Ocean [1]. It consists of rising motion and easterly flow at low levels in the western Pacific and westerly flow at upper levels and sinking motions in the eastern Pacific. The intensity of the WC substantially decreases when the winds in the eastern Pacific weaken, a pattern that, according to Bjerknes, is related to the weakening of the sea surface temperature (SST) gradient. Bjerknes concluded that the WC would not exist in absence of a zonal SST gradient. However, [2] carried out a scale-analysis of the thermodynamic energy equation and verified that both radiative heating and the evaporation rate could be neglected when compared with latent heat release in

${ }^{*}$ Corresponding author. driving the ascent motions in the WC. Consequently, the authors carried out a radiation budget analysis of the equatorial region and noted that there is a near balance between local evaporation and the downward solar energy flux. According to this result, the evaporation rate which Bjerknes considered as one of the main driving forces for the WC could not produce ascending motions over the western Pacific due to attenuation resulting from cloud cover.

[3] employed an Atmospheric General Circulation Model (AGCM) to evaluate changes in the spatial behavior of the WC under different zonal SST gradients and showed that when the zonal SST gradient is completely absent the spatial pattern of the WC is notably disturbed. Their results suggest that the zonal SST gradient is important to modulate spatially the $\mathrm{WC}$, but not to drive it. In order to study the energy and moisture budgets of the WC, [4] designed a set of numerical ex- 
periments with an AGCM and showed that the correlation between precipitation and moisture convergence is stronger than the relationship between precipitation and local evaporation. These results support the idea that rising motions in ascending branches of the WC are related to moisture convergence instead of evaporation as proposed by Bjerknes.

Using a two-box model, representative of a cold and warm pool atmosphere denoted, respectively, by CPA and WPA, [5] suggested that the air cooling over the CPA box representative of a region free of convection would be produced by the horizontal moisture transport from this region toward higher temperature areas; i.e., the WPA which is representative of net upward motions and a region of deep convection. [6] showed that the intensity of the WC, quantified in terms of the magnitude of vertical motions, would be to a first approximation determined by subsidence-induced warming being balanced by radiative cooling over the eastern Pacific. Moreover, according to [6] the descending motions are the main driving of the WC and the upward motions that occur in western Pacific would be a consequence of the former. [7] based on numerical simulation showed that the WC has slowed down due to a decrease in the zonal SST and mean sea level pressure gradient in the last decades. According to the authors, the decrease in the zonal atmospheric overturning circulation above the tropical Pacific Ocean is presumably driven by oceanic rather than atmospheric processes.

From an annual mean analysis of the heat balance of the WC [8] showed that ascending motion in the WC's upward branch is determined by the joint effect of latent heat and radiative cooling processes while infrared radiation loss is associated with sink motions on the WC's descending branch. Once warm air rises and relatively cold air sinks, respectively, over the western and eastern equatorial Pacific basin there is a continuous conversion between potential and kinetic energy; however, what maintains the apparently continuous generation of the kinetic energy reservoir at the expense of available potential energy had not been quantified yet. The importance of measuring the energy reservoirs and the way they are transformed into another kind of energy (potential to kinetic or vice-versa) has been emphasized in many studies of open ([9-16]) and closed ([17-23]) domains. Thus, in order to quantify the generation of potential energy, the conversion between potential and kinetic energy, and the sources and sinks of available potential and kinetic energy, the present study focuses on the atmospheric energetics involved in the $\mathrm{WC}$ and its behavior for strong ENSO phases.

The paper is structured as follows: Section 2 describes the data and methodology used in this work, with an application of the Lorenz energetics technique. In Section 3.1 , we present a volume integrated energy cycle, with an analysis of the energy cycle for normal and ENSO conditions. In Section 3.2, we present the climatological vertical-time distribution of the main energy components relative to Walker circulation domain, stressing the main energy mechanism responsible by the maintenance and strength of the Walker circulation. This is followed by an analysis of the energetics for the Walker circulation domain for a composite of El Niños and La Niñas focusing on the energy patterns which drove the differences in each energetic behaviors (Section 3.3). In Section 4, we present a discussion about the main findings. We conclude in Section 5 with a description of the energy cycle evolved in the maintenance of the Walker circulation and their patterns during ENSO events. Furthermore, we suggest future applications of the energetics to quantify the Walker circulation's intensity changes from a climate change perspective.

\section{Data and Methodology}

To compute the energetics proposed in this study daily mean data of geopotential $(\Phi)$, air temperature $(T)$, zonal $(\mathrm{u})$, meridional (v) and vertical (w) components of the wind velocity in a regular horizontal space of $2.5^{\circ} \times 2.5^{\circ}$ grid resolution from NCEP/NCAR Reanalysis 2 for 12 standard isobaric levels $(1000,925,850,700,600,500$, $400,300,250,200,150$ and $100 \mathrm{hPa}$ ) were used. The data cover a period of 33 years (1979 to 2011) and was extracted from the NOAA-CIRES Climate Diagnostic Center available on the website http://www.cdc.noaa.gov. The computation of the energetics for the Pacific WC is applied to an area limited by the latitudes of $10^{\circ} \mathrm{S}$ and $5^{\circ} \mathrm{N}$, and longitudes $120^{\circ} \mathrm{E}$ and $80^{\circ} \mathrm{W}$. Although the WC is observed globally with branches of varying intensity over all basins, in the present work we concentrate on the largest and strongest cell observed over the Pacific Ocean. A slight asymmetry in relation to the equator is also observed on an annual basis. Figure 1 shows the climatological values of omega and zonal wind over three different latitudinal bands within the $10^{\circ} \mathrm{S}-10^{\circ} \mathrm{N}$ region around the Equator. As shown by this figure, our chosen range of $10^{\circ} \mathrm{S}-5^{\circ} \mathrm{N}$ has a slightly enhanced distinction between the ascending and descending branches between the western and eastern boards of the Pacific sector of the cell. Hence, this area optimizes a balance between ascending and descending motion when calculating the energetics. The slight asymmetry occurs because most of the subsidence on the eastern branch occurs to the south of the Equator, where the waters are significantly colder. Additional tests were performed for several slight variations of the original domain, and the core of our results is unchanged.

Mass integrals required for the computation of the energetics are numerically evaluated for the whole troposphere from 1000 to $100 \mathrm{hPa}$. To compute generation of available potential energy, diabatic heating is required. 
Annual climatology of omega and zonal wind (10S-10N)

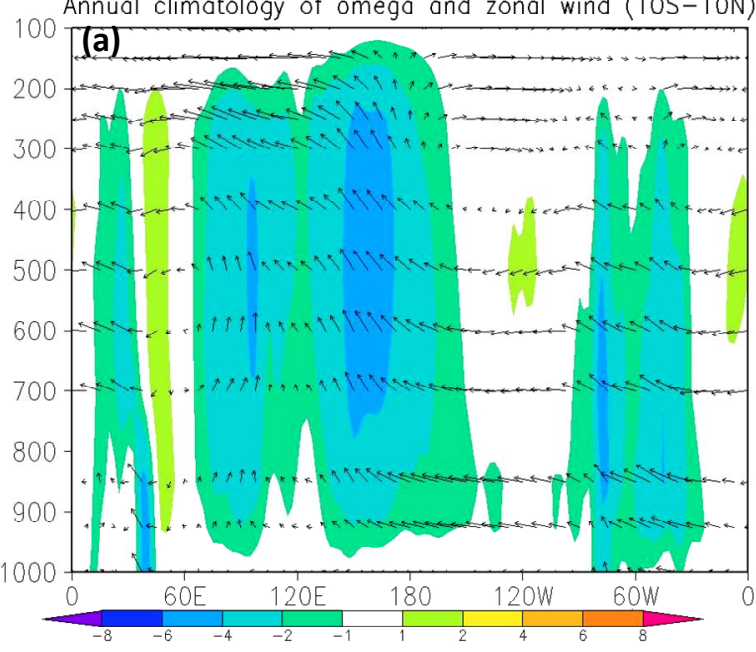

Annual climatology of omega and zonal wind (10S-Equator)

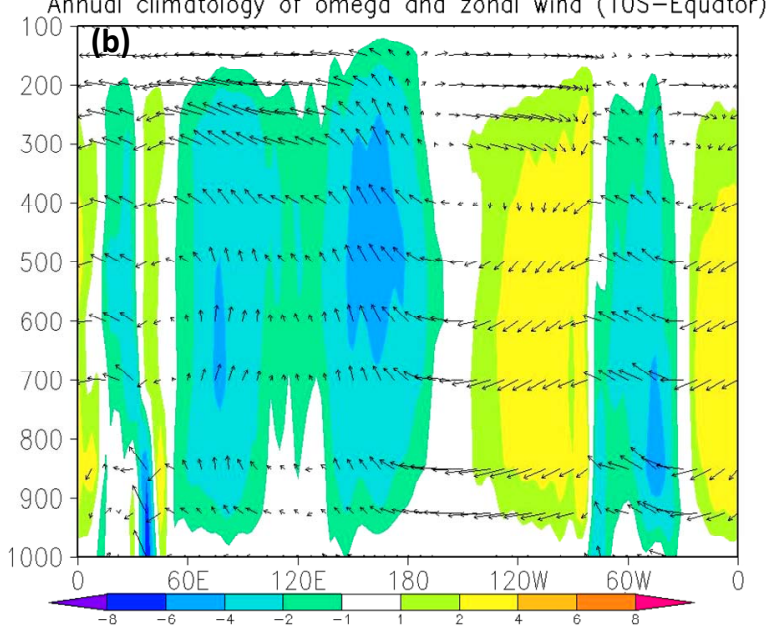

Annual climatology of omega and zonal wind $(10 S-5 \mathrm{~N})$

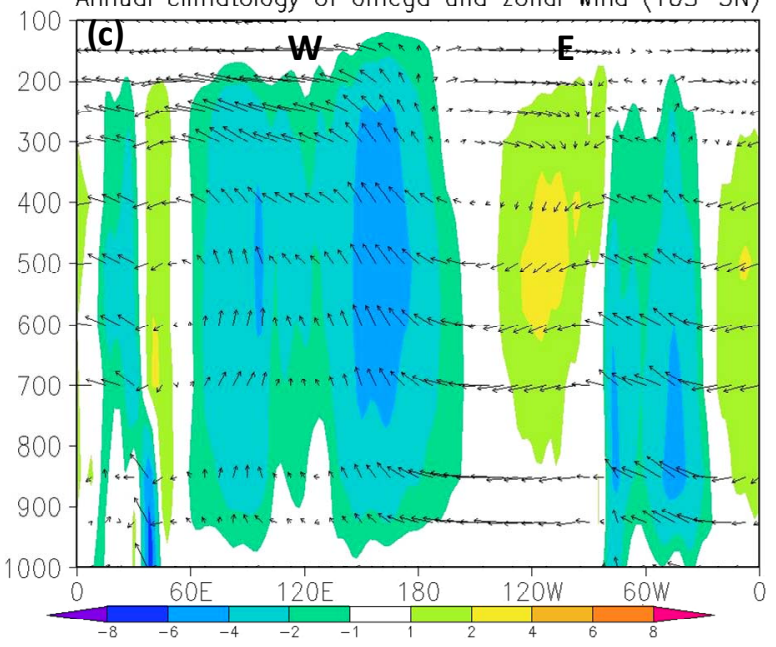

Figure 1. Annual climatology of omega and zonal wind associated with the Walker Circulation for (a) $10^{\circ} \mathrm{S}-10^{\circ} \mathrm{N}$, (b) $10^{\circ} \mathrm{S}$-Equator and (c) $10^{\circ} \mathrm{S}-5^{\circ} \mathrm{N}$ relative to the period of 1979 to 2011. The $W$ and $E$ mark the boundaries of our environmental box that defines the energetics of the Pacific sector of the Walker Circulation.
As this variable is directly produced by the radiation and convection parameterization in numerical models and is classed as type-C variables, we instead compute the diabatic heating as a residual from the balance equations [24]. In this case the residual express the sum of all kinds of diabatic heating involved into the atmosphere, ex: diabatic heating due to the condensation of moisture, sensible heating, diabatic cooling due to thermal radiative processes and short wave radiation. The Lorenz energetics analysis, including generation, conversion and dissipations of kinetic and potential energy are shown in terms of monthly and annual means.

\section{Lorenz Energetics}

A traditional and compact form of presenting the spatial domain of atmospheric energetic was firstly suggested by [25]. In this energetic frame of reference the kinetic as well as the available potential energy are resolved into the amounts associated with the zonally averaged fields of motion and mass and the amounts associated with eddies $([25,26])$. Lorenz defined zonal kinetic energy (KZ) as the amount of kinetic energy which would exist if motion where purely zonal. Naturally, both $\mathrm{u}$ and $\mathrm{v}$ are included in this definition, as a spatial average taken over a given latitude (see appendix A). On the other hand, eddy kinetic energy (KE) would be the excess of kinetic energy over KZ or additionally the kinetic energy related to the eddies in absence of zonal motion. Each energy type is connected by conversion terms, which are produced or destroyed by sources or sink terms. Furthermore, as discussed earlier, we here use the concept of limited area for the energetics where the "zonal" and "eddy" components are expressed as averages within a horizontal domain incorporating the ascending and descending branches of the Pacific WC. Within this framework the calculation of the transport across the boundaries is also relevant. As we will discuss in the next section, those term are in general at least one order of magnitude less than the energy conversion terms, adding to the robustness of our findings.

Figure 2 shows that the Lorenz energy cycle consists of four boxes denoting primary energy exchanges, including the zonal and eddy parts of the potential and kinetic energies within each box, with their connections given by energy conversion terms representing different dynamical process in the atmosphere (for instance, baroclinic and barotropic growth processes). The conversion terms are labeled as CZ, CA, CE and CK, respectively, denoting the conversion from AZ (zonal available potential energy) into $\mathrm{KZ}$ (zonal kinetic energy), $\mathrm{AZ}$ into $\mathrm{AE}$ (eddy available potential energy), AE into KE (eddy kinetic energy), and KE into KZ respectively. The complete set of boundary transport terms resulting from the limited area calculation are also indicated (terms starting with "B"). The magnitude of those terms will be dis- 


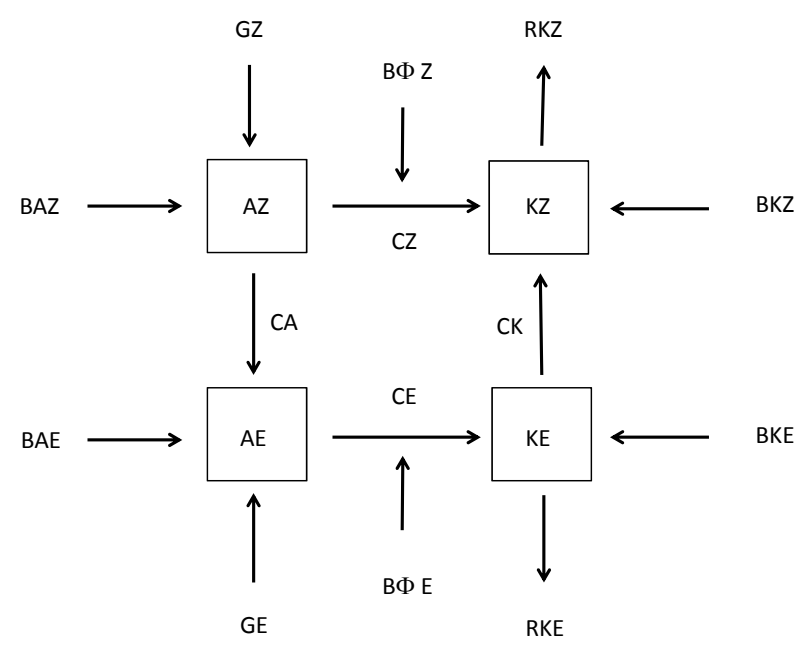

Figure 2. Lorenz energy diagram for an open domain.

cussed in the next section.

According to [25], the CZ term depends upon the covariance between zonal means of vertical velocity and temperature. $\mathrm{CZ}$ reflects the growth of $\mathrm{KZ}$ at the expense of $\mathrm{AZ}$ when there is warm air rising and cold air sinking latitudinally. The CA term depends upon the relation between the meridional transport of sensible heat and the meridional gradient of zonal averaged temperature, and the vertical transport of sensible heat and the vertical gradient of zonal averaged temperature. The CE term depends upon the covariance between the omega vertical motion and temperature. According to this conversion, the term $\mathrm{KE}$ increases at the expense of $\mathrm{AE}$ when warm air rises and cold air sinks longitudinally. These three forms of energy quantities are known as baroclinic conversions as they are related with heat transport. The CK term, named as barotropic conversion, depends upon the horizontal (zonal and meridional) and vertical transport of angular momentum. For instance, if $\mathrm{CZ}$ is positive (negative), there is local growth of $\mathrm{KZ}$ (AZ) at the expense of $\mathrm{AZ}(\mathrm{KZ})$.

Negative values of conversion terms are not explicitly displayed in the energy frame, but they are illustrated by the inverse direction of the arrows relative to original flow. The classic Lorenz diagram contains generation of available potential energy and dissipation of kinetic energy for zonal and eddy parts (GZ, GE, DZ and DE). The generation of $\mathrm{AZ}$ (AE) occurs when there is meridional (zonal) differential heating.

As discussed before, in an open area of the atmosphere the energy budget is complicated by the inclusion of nonzero boundary transports of potential and kinetic energy. To take those into account, [27] included four new components of the energy budgets representing the transport of $\mathrm{AZ}, \mathrm{AE}, \mathrm{KZ}$ and $\mathrm{KE}$ (denoted, respectively, by BAZ, BAE, BKZ and BKE) into or out of the boundaries (Figure 2). In addition, [27] considered the appearance of $\mathrm{KZ}$ and $\mathrm{KE}$ within the volume of the limited area associated with the work produced at its boundaries, $\mathrm{B} \Phi \mathrm{Z}$ and $\mathrm{B} \Phi \mathrm{E}$, respectively. These additional energy quantities are explicitly computed here and added into the Lorenz box diagram.

Bellow we show the set of energy equations representing the Lorenz energy cycle used in this work.

$$
\begin{array}{r}
\frac{\partial \mathrm{AZ}}{\partial t}=-\mathrm{CZ}-\mathrm{CA}+\mathrm{BAZ}+\mathrm{GZ} \\
\frac{\partial \mathrm{AE}}{\partial t}=\mathrm{CA}-\mathrm{CE}+\mathrm{BAE}+\mathrm{GE} \\
\frac{\partial \mathrm{KZ}}{\partial t}=\mathrm{CK}+\mathrm{CZ}+\mathrm{BKZ}+\mathrm{B} \Phi \mathrm{Z}-\mathrm{DZ} \\
\frac{\partial \mathrm{KE}}{\partial t}=\mathrm{CE}-\mathrm{CK}+\mathrm{BKE}+\mathrm{B} \Phi \mathrm{E}-\mathrm{RKE}
\end{array}
$$

The equations of the four amounts of energy (AZ, AE, $\mathrm{KZ}$ and $\mathrm{KE}$ ), their conversions ( $\mathrm{CA}, \mathrm{CE}, \mathrm{CZ}$ and $\mathrm{CK}$ ), generation (GE and GZ), dissipation (RKZ and RKE) and boundary flux terms (BAZ, BAE, BKZ and BKE) were applied successfully in a series of papers exploring the energetics of open domains ([14,24,25,28]).

The equations of energy, conversions and boundary fluxes used in this study are displayed in the Appendix. $\mathrm{B} \Phi \mathrm{Z}$ and $\mathrm{B} \Phi \mathrm{E}$ terms represent the dynamical mechanisms which produce or destroy kinetic energy. As described by [27], this is due to the fact that $B \Phi Z, B \Phi E$, $\mathrm{CZ}$ and $\mathrm{CE}$ derivatives involve a single term in the form V. $\nabla \Phi$, which represents the appearance of kinetic energy via a cross-isobaric flow towards low pressure. The destruction of kinetic energy occurs when there is crossisobaric flow towards the high pressure.

\section{Results}

\subsection{Volume Integrated Energy Cycle}

The Lorenz energy cycle for the climatology, El Niño and La Niña years (marked in colors inside the boxes) for the summer season is shown in Figure 3. The convention of the conversion cycle is given by the direction of the arrows as in Figure 2. The energy diagram shows a $6.7 \%$ decrease and a $15 \%$ increase in $\mathrm{AZ}$, respectively for $\mathrm{El}$ Niño and La Niña years. AE is reduced by $39 \%$ during El Niños, while AE increases by $38.2 \%$ in La Niña years. The values of kinetic energy reservoirs present the same behavior, i.e., during El Niño years they are weakened while in cold phases of ENSO they are strengthened: $29.1 \%(22.8 \%)$ decreases in KZ (KE) for El Niño conditions and $29.1 \%(14.6 \%)$ increases in $\mathrm{KZ}(\mathrm{KE})$ for $\mathrm{La}$ Niña conditions are observed.

The boundary flux of AZ (BKZ) is negative for all composites, working as a sink of zonal available energy, 


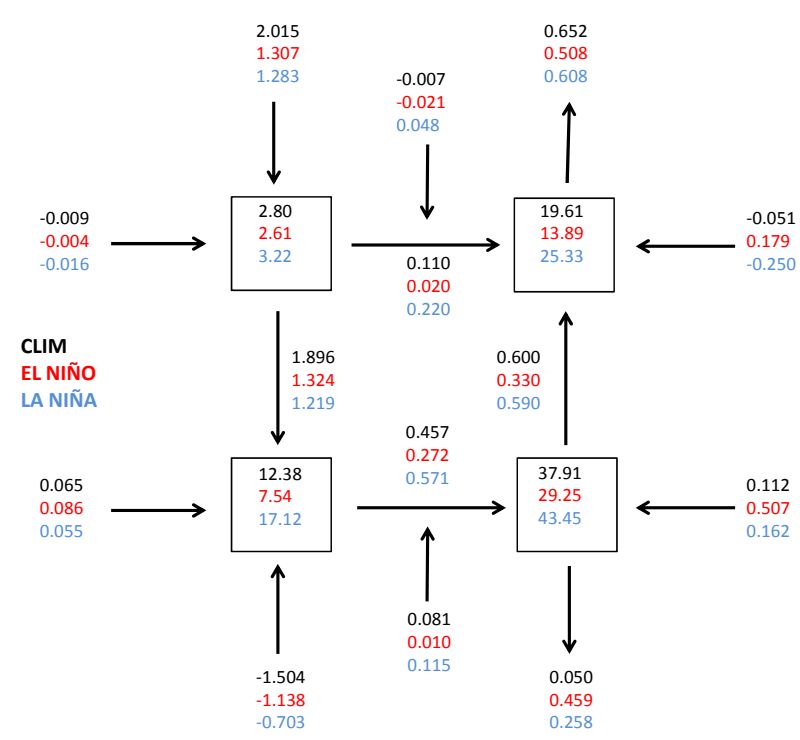

Figure 3. Lorenz energy cycle for the climatology, composite of El Niño (red) and composite of La Niña (blue). All values are representative of DJF. Units are $10^{5} \mathrm{~J} \cdot \mathrm{m}^{-2}$ for energy terms and $W \cdot \mathrm{m}^{2}$ for conversion, flux and work done terms. All conventions follow the standard diagram outlined in Figure 2.

while BKE acts as a source of AE. Both terms undergo magnitude changes during different phases of ENSO. However, due to their low magnitudes relative to the other terms in the energy balance their contributions to the energy reservoirs are small. Climatologically, BKZ acts as sink of KZ. During El Niño and La Niña years BKZ acts as energy source and sink, respectively. The boundary flux of KE, however, is positive, showing that this term contributes to the rising of KE for all conditions. Its contribution is reduced for El Niño conditions, and increased during La Niña years.

As can be seen from the diagram we also note that the energy cycle as a whole is weakening during El Niño years and strengthening during La Niña years. The energy diagram reveals that the weaker/stronger Lorenz energy cycle results from a decrease/increase in the conversion terms during El Niño/La Niña years.

\subsection{Climatology of Energy and Conversion Terms}

Figure 4 shows the mean annual vertical distribution of the generation and energy terms for the period 19792011. The generation of zonal available potential energy is stronger (with negative values) in the upper levels in most part of the year (Figure 4(a)). The values of generation of eddy available potential energy (Figures 4(b)) are positively stronger during the SH summer in the upper levels. A small patch of positive values is also seen near the surface, particularly for the generation of zonal potential energy. The negative upper level values can be interpreted as potential energy destruction due to the lowest air temperature in the upper troposphere. The negative values of GZ is too a consequence of the relatively cold air ascent and a sink of the relatively warm air.

The pattern of potential energy is showed in Figures 4(c) and (d). The field is relatively smooth with greater values either close to the surface or around $300 \mathrm{hPa}$, clearly associated with the stratification of the atmosphere ([19]). The kinetic energy (Figures 4(e) and (f)) reveals a very different pattern, with a marked upper level maximum in late SH winter (Figure 4(e)) and a more uniform distribution of its eddy component (Figure 4(f)) with maximum values during the $\mathrm{SH}$ summer in the $100-200 \mathrm{hPa}$ layer. This field implies an influence of the jet stream in the southern boundary of the domain at a time when the Hadley cell is at its northernmost position. The high values of kinetic and available potential energy in the upper troposphere are in good agreement with [19, 29].

Figure 5 shows the climatology of the conversion terms for the same period of Figure 4. The conversion cycle starts with positive values of CZ (Figure 5(a)) indicating how zonal kinetic energy is generated from available potential energy. The conversion is maximized around $300 \mathrm{hPa}$ from March to December where the zonal available potential energy is greater. CA is predominantly negative in the upper levels (Figure 5(b)) indicating a production of zonal available potential energy in the expanse of eddy available potential energy in the $400-200 \mathrm{hPa}$ layer. This would be expected as the domain is in the tropics and would act as a sink of eddies propagating within Rossby ways from higher latitudes. The remaining baroclinic term CE has a reasonably uniform pattern in the mid and upper levels indicating that weak eddy disturbances are also observed to form on average (Figure 5(c)). The energy cycle is completed by a marked barotropic (production of KE by the transfer of momentum) conversion during SH summer (Figure 5(d)). Thus, in a climatological perspective AZ continuously acts as a source of KZ in late SH summer from low levels to the high troposphere, while KE partially supports the generation of $\mathrm{KZ}$ via barotropic conversion in the upper levels during DJF.

\subsection{Energy and Conversion Terms during El Niño and La Niña Years}

The results above help put in perspective the behavior of the energetics relevant to the Walker circulation. Some of the variability encountered is similar to the global energetics depicted earlier in the literature ([30]), with a vertical profile typical of the tropical/subtropical interface area. Before we attempt to calculate the energy conversion anomalies associated with ENSO it is important that 

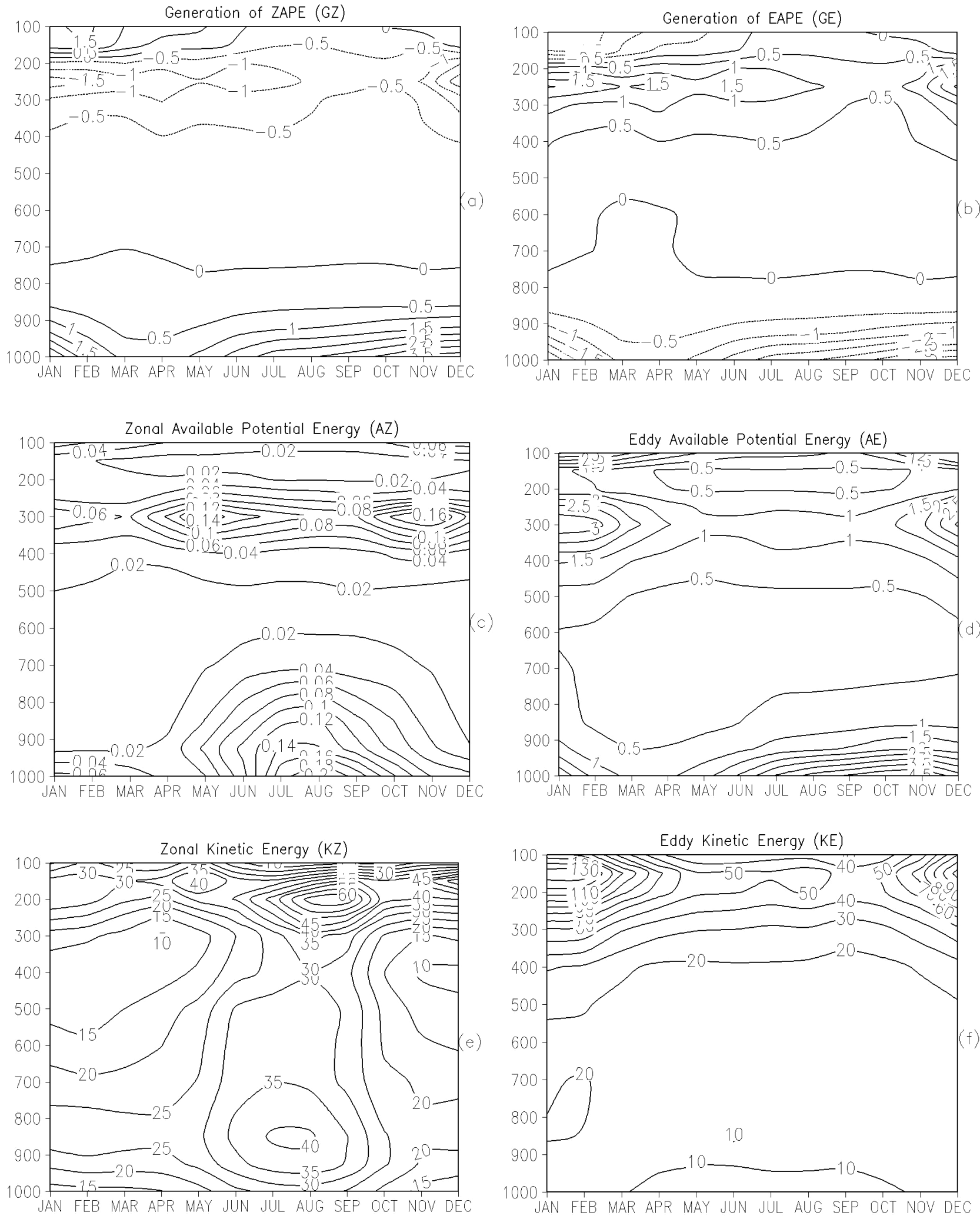

Figure 4. Vertical cross sections of generation of zonal available potential energy (a); Eddy available potential energy (b); zonal available potential energy (c); Eddy available potential energy (d); Zonal kinetic energy (e) and Eddy kinetic energy (f) terms for the period of $1979-2011$. Units are $W \cdot \mathrm{m}^{-2}(100 \mathrm{hPa})^{-1}$ for generation terms and $\mathrm{J} \cdot \mathrm{m}^{-2}(100 \mathrm{hPa})^{-1}$ for kinetic and potential energy. 

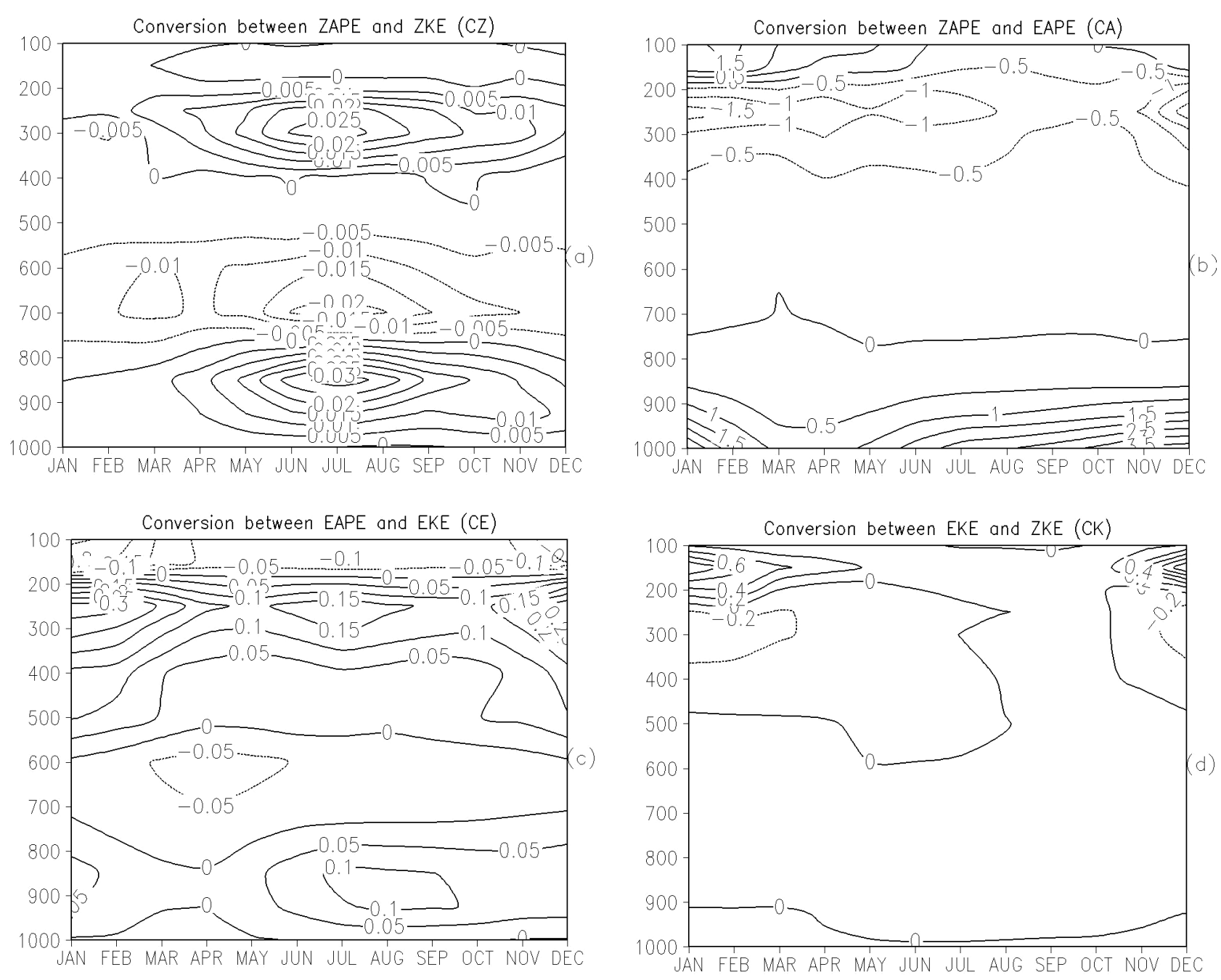

Figure 5. Vertical cross sections of conversion terms CZ (a); CA (b); CE (c); and CK (d) for the period of 1979-2011. The units are $\mathrm{W} \cdot \mathrm{m}^{-2}(100 \mathrm{hPa})^{-1}$.

we test whether the anomaly patterns are robust for an open area energetics such as the one adopted in this work. Figures 6(a)-(f) show the climatological boundary fluxes and work pressure terms calculated following. It is immediately apparent that most terms have a very low order of magnitude, presenting a moderate degree of seasonal variability implying that the transport across the boundaries may be slightly enhanced depending on the properties of the large scale flow. The work pressure terms are of even lower order of magnitude compared to the transport terms. As we keep this result in mind, it will be easily apparent that the energy conversion terms denoting the anomalies associated with the ENSO phase (to be discussed next) are generally at least one order of magnitude larger than the aforementioned terms, which is a clear indication that the interpretation of our results is not contaminated by an artificial signature arising from transport from outside the domain. Ultimately this implies that our interpretation stands as an enhanced energy conversion anomaly within the domain responding to the ENSO phase. This is not surprising, as our original domain is fairly large in order to account for such a robust signature. The anomalies associated with the ENSO phase are discussed below.

Figure 7 shows the Lorenz energy terms for El Niño years from year zero (genesis) to year +1 (maturation and demise), with the anomalies (defined here as the difference between a composite of five El Niños and the climatology) superposed in color. From this result we can see that El Niño years have a clear association with decreased eddy available potential energy in the upper levels during the early stage of year +1 (Figures 7(a) and (b)). The zonal kinetic energy is slightly reduced in both upper and lower atmosphere (Figure 7(c)). In the upper levels the reduction of zonal kinetic energy is observed from the late of year zero to the early of year +1 , while the reduction in the lower levels occurs in the early and final stage of the El Niño (April of year zero to April of 

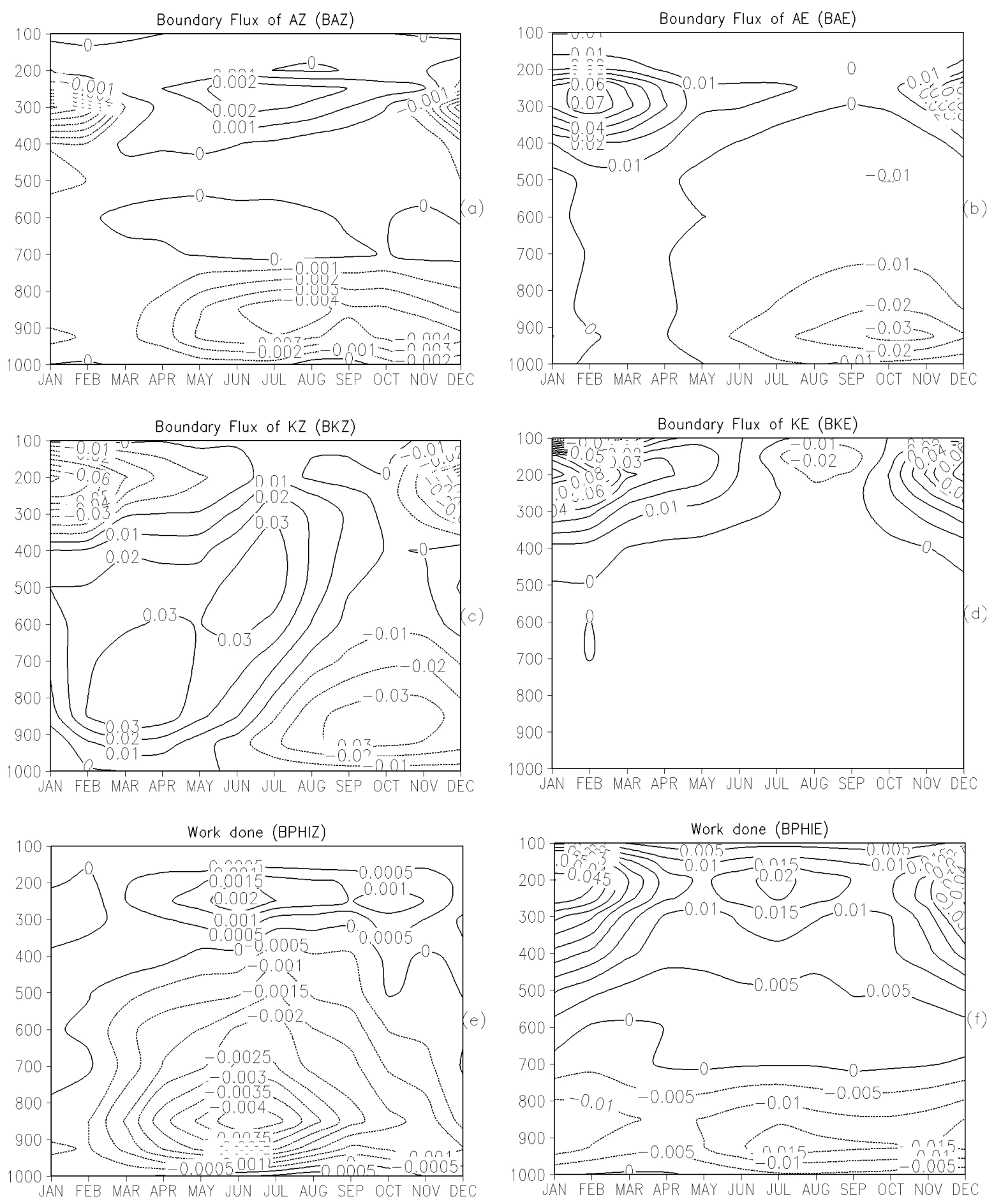

Figure 6. Vertical cross sections of boundary flux of AZ (a); Boundary flux of AE (b); Boundary flux of KZ (c); Boundary flux of KE (d); BPHIZ (e) and BPHIE (f) terms for the period of 1979-2011. Units are $\mathrm{W} \cdot \mathrm{m}^{-2}(100 \mathrm{hPa})^{-1}$.

year +1$)$. As observed in Figure 6(d) the El Niño events is also related to a strong decrease in the values of eddy kinetic energy in the upper levels from September to December of year zero to January to July of year +1 . This suggests that, although the Walker circulation's intensity is reduced during El Niño years, the propaga- tion of baroclinic storms within the area is somewhat enhanced.

The Lorenz conversion terms for El Niño years from year zero to year +1 are presented in Figure 8. From July of year zero to July of year +1 there are positive anomalies of CZ (Figure 8(a)). This condition indirectly pro- 

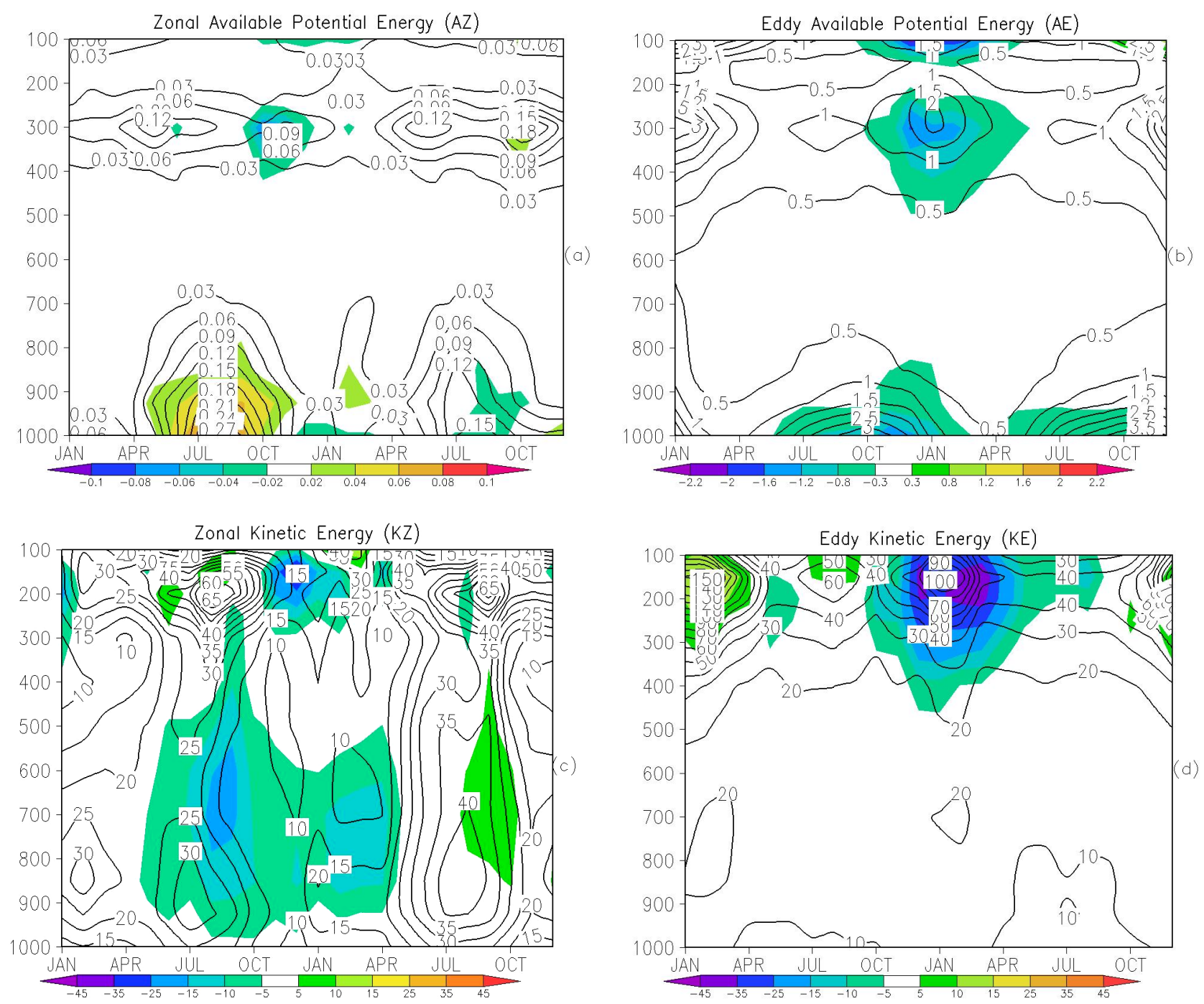

Figure 7. Vertical cross sections of the Lorenz energy terms (AZ, AE, KZ and KE) for a composite of five El Niño episodes: 1982-1983, 1986-1987, 1991-1992, 1997-1998 and 2009-2010 (contour lines), and changes relative to climatological values (color shaded). Units are $\mathbf{J} \cdot \mathrm{m}^{-2}(100 \mathrm{hPa})^{-1}$.

duces a deficit of eddy kinetic energy by the conversion term $\mathrm{CE}$, once more zonal available potential energy is used to produce zonal kinetic energy instead of eddy available potential energy. The negative anomalies of zonal and eddy kinetic energy reservoirs (Figures 7(c) and (d)) are in agreement with negative anomalies of CE and CK. Negative anomalous values of CE suggest less energy to be converted into eddy kinetic energy, while negative anomalous values of $\mathrm{CK}$ in the upper levels mean less energy to be converted into zonal kinetic energy from the eddies.

[31,32] showed a decrease in the intensity of the WC as the climate warms. According to the authors this occurs due to a decreasing in the frequency of strong updrafts and an increasing in the frequency of weak updrafts. [8] points to a strong decrease of the $\mathrm{WC}$ in an environment with doubled $\mathrm{CO}_{2}$ concentration, inducing a significant rising in the SST over the Pacific Ocean. According to [33] the slowdown of the $\mathrm{WC}$ in a warmer atmosphere is a response to a decrease in the zonal SST gradient, a pattern associated with El Niño. From model simulations [33] showed that the WC slowdowns as a response to the eastward shift of atmospheric convection from the Indonesian maritime continent to the central tropical Pacific.

Figure 9 shows the energy terms associated with year zero and year +1 of the La Niña composite within the domain of the Walker circulation. From Figure 9(a) we can see that only modest anomalies are observed during La Niña years in the zonal available potential energy. Importantly, these anomalies are of opposite sign compared to the pattern observed during El Niño years (Figure 7(a)). The eddy available potential energy presents a marked upper level increase towards the beginning of 

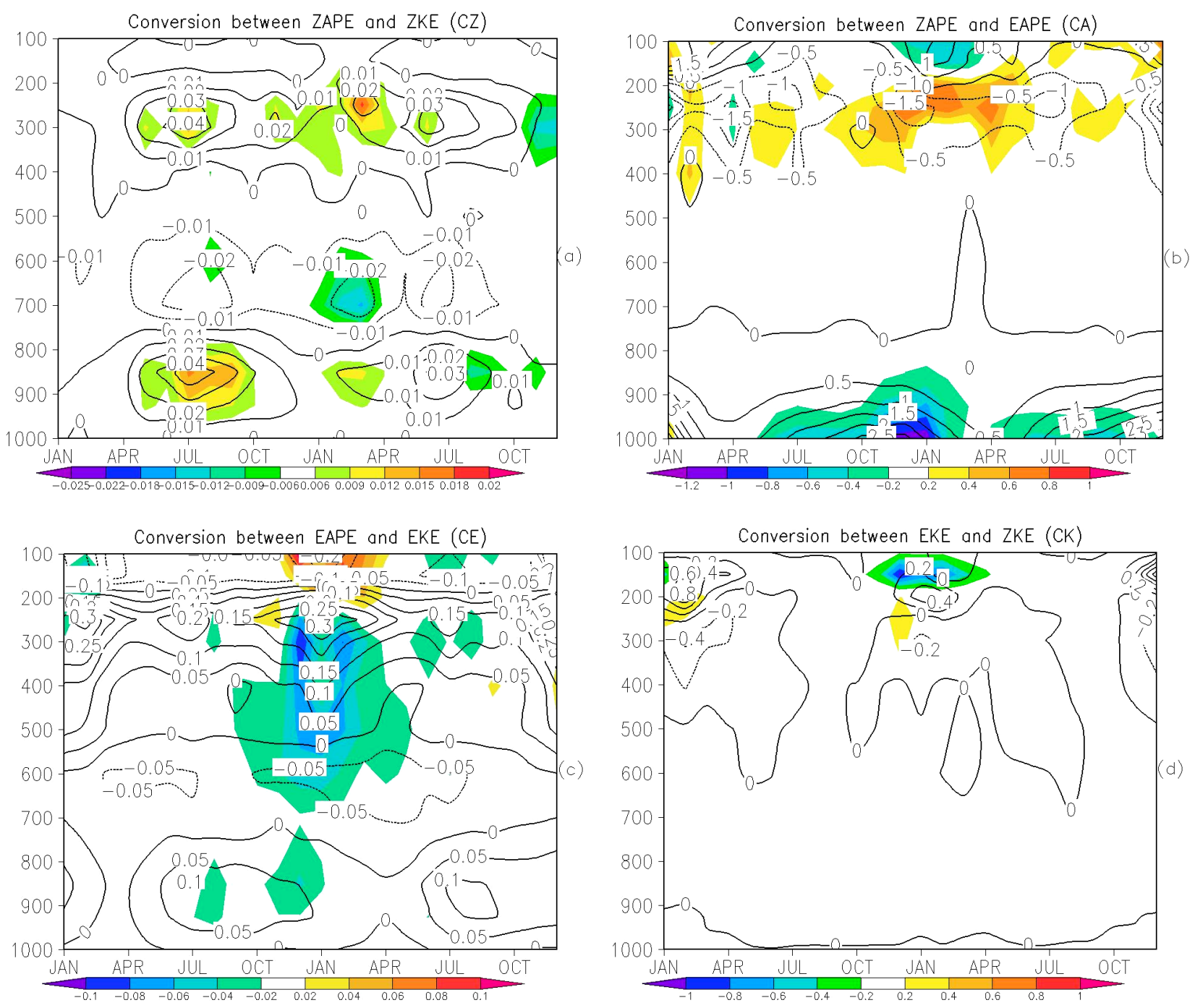

Figure 8. Vertical cross sections of the Lorenz conversion terms (CZ, CA, CE and CK) for a composite of five El Niño episodes: 1982-1983, 1986-1987, 1991-1992, 1997-1998 and 2009-2010 (contour lines), and changes relative to climatological values (color shaded). Units are $\mathrm{W} \cdot \mathrm{m}^{-2}(100 \mathrm{hPa})^{-1}$.

year +1 (Figure 9(b)), contrasting with the opposite behavior observed during El Nino years. Significant changes are also observed in the zonal kinetic energy (Figure 9(c)). These are approximately opposite to the anomalies observed during El Niño years, especially in the genesis phase. The overall patterns, although approximately opposite between the positive and negative phases, is not exactly symmetrical. Rather, the increased kinetic energy seen in La Niña years (as opposed to the decreased kinetic energy during El Niño years) cannot be coming from anomalies in potential energy alone. This implies a possible teleconnection with stronger jet streams propagating into the area of study during La Niña years. Finally, the eddy kinetic energy during La Niña years (Figure 9(d)) also features an increase.

The conversion patterns for La Niña years are shown in Figure 10. The production of zonal kinetic energy from zonal available potential energy (Figure 10(a)) shows a reduction for most of year zero until the end of year +1 . An opposite pattern is seen in the conversion from zonal available potential to eddy available potential energy (CA, Figure 10(b)) relative to the composite of positive phase of ENSO. This shows that this particular conversion, which is associated with sensible heat transport, is also affected by ENSO. No coherent patterns is seen in the conversion term CE (Figure 10(c)), but there is an overall suggestion of decrease in the upper levels $(200 \mathrm{hPa})$ and increase in the mid-levels $(500 \mathrm{hPa})$. Finally, the barotropic conversion (CK, Figure 10(d)) is approximately the opposite from what was observed during El Niño years, implying an atmospheric balance to try to restore the eddy kinetic energy lost during La Niña years (negative values around $200 \mathrm{hPa}$ ). In the very upper levels the pattern of $\mathrm{CK}$ is a mirror-like of the one 

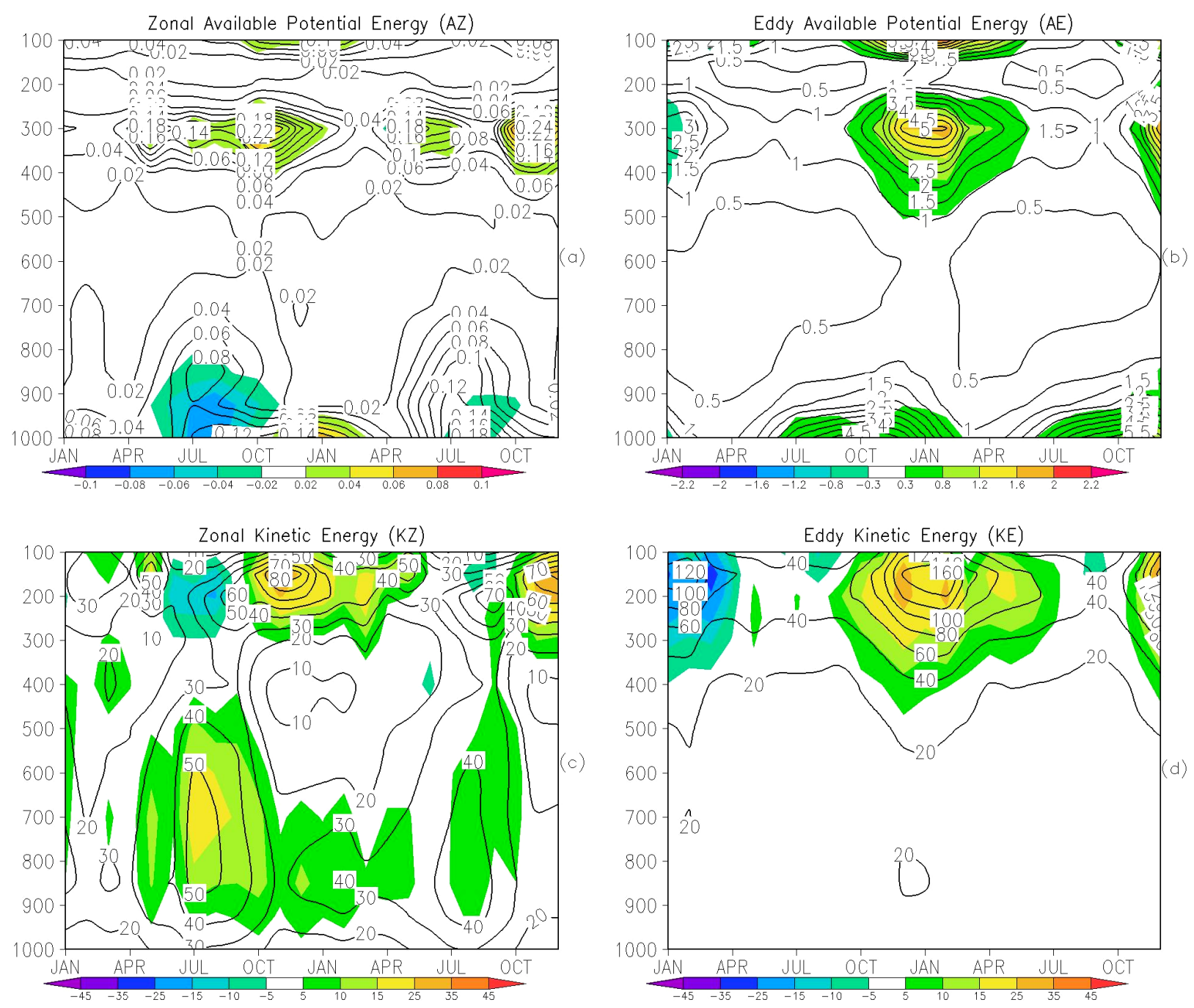

Figure 8. Vertical cross sections of the Lorenz conversion terms (CZ, CA, CE and CK) for a composite of five EI Niño episodes: 1982-1983, 1986-1987, 1991-1992, 1997-1998 and 2009-2010 (contour lines), and changes relative to climatological values (color shaded). Units are $\mathrm{W} \cdot \mathrm{m}^{-2}(100 \mathrm{hPa})^{-1}$.

observed in the area of the jet streams, possibly reflecting the propagation of stratospheric gravity waves.

\section{Discussion}

In this article, we have studied changes in the Walker circulation inferred by changes in the profile of the Lorenz energetics associated with ENSO. We first compiled a robust climatology of energy and conversion terms associated with the large scale domain representative of the Walker cell circulation over the Pacific Ocean, showing how the energetics contributes to the establishment of the Walker circulation. The potential energy shows two defined maxima at the surface and at about $300 \mathrm{hPa}$ year round, while the kinetic energy implies a well defined upper level jet stream with maximum amplitude in late $\mathrm{SH}$ winter.

The conversions associated with those terms above show that the jet stream associated with the upper level branch of the cell is formed primarily via barotropic "decay" of eddy kinetic energy, and also partially via conversion using the existing reservoir of potential energy. There is upper level dissipation of eddy potential energy compatible with what would be expected of the tropical circulation, with some generation of eddy kinetic energy in the mid-levels.

The results show that ENSO has a marked impact on the dynamics of these energy exchanges, with an approximate reversal of the spin up of the Pacific Walker circulation between La Niña (circulation enhanced) and El Niño phase (circulation suppressed). While the kinetic energies are reduced throughout year zero and year +1 during the warm phase composite, the conversion terms reveal that the anomalies peak during the genesis of the events and reverse during their demise. 

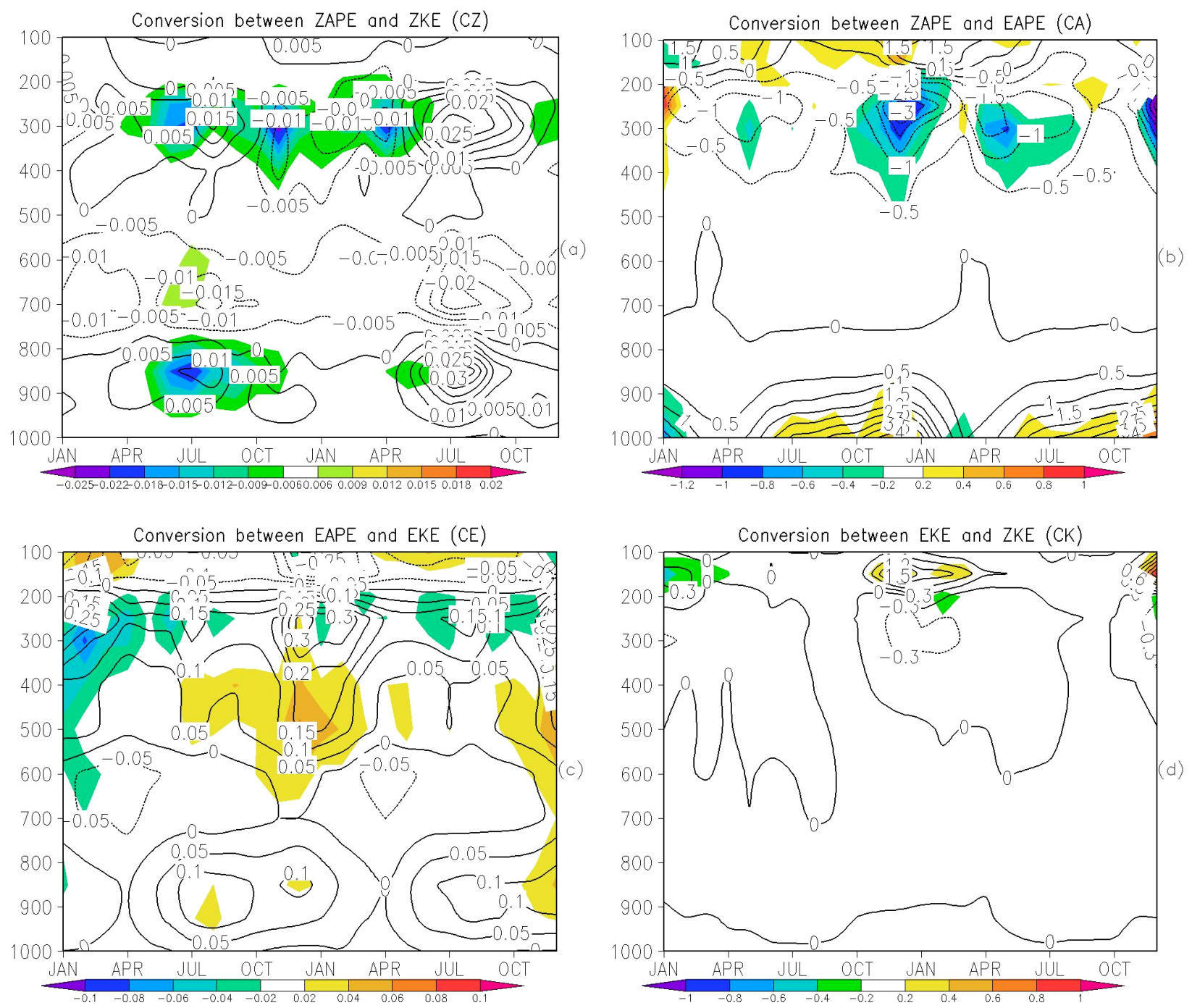

Figure 10. Vertical cross sections of the Lorenz conversion terms (CZ, CA, CE and CK) for a composite of five La Niña episodes: 1984-1985, 1988-1989, 1998-1999, 1999-2000 and 2010-2011 (contour lines), and changes relative to climatological values (color shaded). Units are $\mathrm{W} \cdot \mathrm{m}^{-2}(100 \mathrm{hPa})^{-1}$.

During La Niña years zonal available potential energy is reduced and the kinetic energy shows an opposite behaviour to what is seen during the warm ENSO phase. This suggests that the source of the increased circulation during La Niña years is a greater conversion rate from the already existent potential energy, rather than changes in the horizontal and vertical stratification. As a result, it is plausible to say that while El Niño years see a modified reservoir of potential energy, during La Niña years a significant acceleration of the circulation is measured. This is similar to saying that La Niña simply reinforces the climatological circulation.

The remarkable symmetry between the composites used for the energy calculations is shown in Figure 11, where the SST anomalies over the Niño 3.4 area are plotted for El Niño and La Niña years for years zero and year +1 . We also observe that the positive and negative anomalies have similar order of magnitude, which makes the comparison robust.

The onset for both El Niño and La Niña occurs around MJJ of year zero, when the threshold $\pm 0.5^{\circ} \mathrm{C}$ is reached. This corresponds well with the start of the anomalous phase observed in the energetics (compare Figures 7 with 8 and 10). It is also interesting to observe that after demise El Niños tend to be followed by the opposite phase (La Niña), whereas La Niñas are also followed by another La Niña.

The energetics here discussed pertain to the large scale environment associated with the Walker cell, while attribution of cause and effect between the energetics and the atmospheric anomalies is not as straightforward as one might think. Here the energetics anomalies are triggered at about the same time as ENSO, leaving an open interpretation as to how the changes are transmitted to 


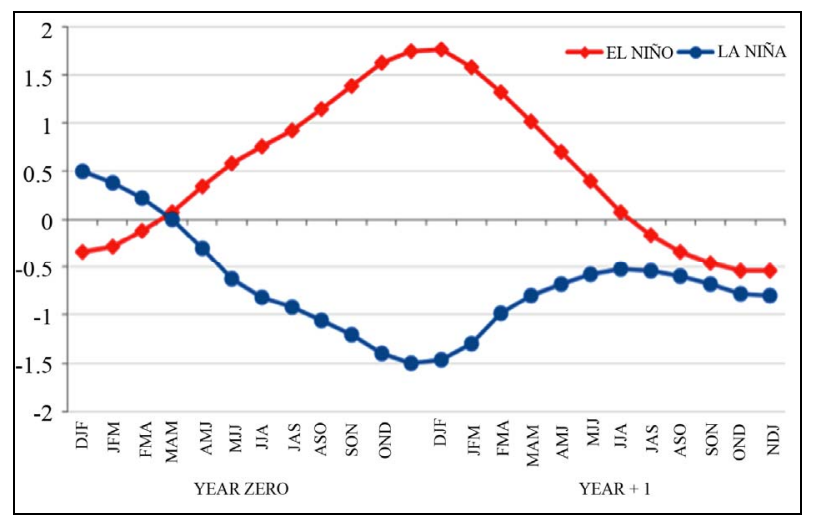

Figure 11. Composite of Warm (1982-1983, 1986-1987, 19911992, 1997-1998 and 2009-2010) and cold (1984-1985, 19881989, 1998-1999, 1999-2000 and 2010-2011) ENSO episodes based on a threshold of $+/-0.5^{\circ} \mathrm{C}$ for the Oceanic Niño Index 3.4 region $\left(5^{\circ} \mathrm{N}-5^{\circ} \mathrm{S}, 120^{\circ} \mathrm{W}-170^{\circ} \mathrm{W}\right)$ using monthly running means of ERSST.v3b (Extended Reconstructed sea surface temperature) anomalies. Source:

http://www.cpc.ncep.noaa.gov/products/analysis_monitorin g/ensostuff/ensoyears.shtml.

the energetics in the first place. As pointed out in earlier work ([9-18,21-23]) the Rossby wave propagation can be influenced by the state of the energetics, as it draws energy from the environment, but the energetics is in turn also influenced by the weather anomalies.

\section{Final Remarks}

This is the first time that the atmospheric energetics associated with the WC and its behavior for ENSO events are quantified. While the Lorenz energetics was originally derived from a dry hydrostatic atmosphere, the interpretation of the energy formulation arises from the contribution of the observed circulation, i.e., $\mathrm{u}, \mathrm{v}$ and $\mathrm{w}$. In this sense, the impact of moisture arises indirectly as the latent heat release will induce pressure and wind changes within the energy box that contains the ascending and descending branches of the WC. While the use of virtual temperature does not cause any significant impact on our results, the study of the specific contribution of latent heat release is beyond the scope of this study. As a recommendation for future work, this technique could also be applied to evaluate the robustness of the $\mathrm{WC}$ in a climate change perspective relatively to the $\mathrm{CO}_{2}$ increasing projected in different scenarios. In particular, the results presented in this paper show that the energetics can also be used to help corroborate the hypothesis that the WC has been slowing down during the 20th century ([16,31,34-36]), or whether it has actually intensified [37]. We note, however, that our definition encompasses only the Pacific sector of the WC. A future deceleration of the WC under global warming scenarios has also been hypothesized in recent studies $([33,38])$.

\section{Acknowledgements}

JAV and TA were supported by CNPq (150356/2011-0). TA also has the support from the FAPESP (08/58101-9), CLARIS LPB and INCLINE/USP. ABP would like to acknowledge the ARC (Australian Research Council) for funding parts of this work.

\section{REFERENCES}

[1] J. Bjerknes "Atmospheric Teleconnections from the Equatorial Pacific," Monthly Weather Review, Vol. 97, No. 3, 1969, pp. 163-172. http://dx.doi.org/10.1175/1520-0493(1969)097<0163:AT FTEP $>2.3 . \mathrm{CO} ; 2$

[2] A. G. Cornejo-Garrido and P. H. Stone, "On the Heat Balance of the Walker Circulation," Journal of the Atmospheric Sciences, Vol. 34, No. 8, 1977, pp. 1155-1162. http://dx.doi.org/10.1175/1520-0469(1977)034<1155:OT HBOT $>2.0 . \mathrm{CO} ; 2$

[3] R. M. Chervin and L. M. Druyan, "The Influence of Ocean Surface Temperature Gradient and Continentality on the Walker Circulation," Monthly Weather Review, Vol. 34, 1984, pp. 1155-1162.

[4] P. H. Stone and R. M. Chervin, "The Influence of Ocean Temperature Gradient and Continentality on the Walker Circulation. Part II: Prescribed Global Changes," Monthly Weather Review, Vol. 112, No. 8, 1984, pp. 1524-1543. http://dx.doi.org/10.1175/1520-0493(1984)112<1524:TIO OST>2.0.CO;2

[5] R. T. Pierrehumbert, "Thermostats, Radiator Fins, and the Local Runaway Greenhouse," Journal of the Atmospheric Sciences, Vol. 52, No. 10, 1995, pp. 1784-1806. http://dx.doi.org/10.1175/1520-0469(1995)052<1784:TR FATL $>2.0 . \mathrm{CO} ; 2$

[6] J. I. Yano, W. W. Grabowski and M. W. Moncrieff, "MeanState Convective Circulation over Large-Scale Tropical SST Gradients," Journal of the Atmospheric Sciences, Vol. 59, No. 9, 2002, pp. 1578-1592. http://dx.doi.org/10.1175/1520-0469(2002)059<1578:MS $\mathrm{CCOL}>2.0 . \mathrm{CO} ; 2$

[7] H. Tokinaga, S. P. Xie, A. Timmermann, et al., "Regional Patterns of Tropical Indo-Pacific Climate Change: Evidence of the Walker Circulation Weakening," Journal of Climate, Vol. 25, No. 5, 2012, pp. 1689-1710. http://dx.doi.org/10.1175/JCLI-D-11-00263.1

[8] J. A. Veiga, V. B. Rao and S. H. Franchito, "Annual Mean Analysis of the Tropical Heat Balance and Associations with the Walker Circulation," Brazilian Journal of Meteorology, Vol. 26, 2011, pp. 1-8.

[9] A. Favre, B. Hewitson, M. Tadross, et al., "Relationships between Cut-Off Lows and the Semiannual and Southern Oscillations," Climate Dynamics, Vol. 38, No. 7-8, 2012, pp. 1473-1487. http://dx.doi.org/10.1007/s00382-011-1030-4

[10] E. Dal Piva, M. A. Gan and V. B. Rao, "Energetics of Winter Troughs Entering South America," Monthly Weather Review, Vol. 138, No. 4, 2010, pp. 1084-1103.

[11] C. A. Davis, "Simulations of Subtropical Cyclones in a 
Baroclinic Channel Model," Journal of the Atmospheric Sciences, Vol. 67, No. 9, 2010, pp. 2871-2892. http://dx.doi.org/10.1175/2010JAS3411.1

[12] J. M. Cordeira and L. Bosart, "The Antecedent LargeScale Conditions of the 'Perfect Storms' of Late October and Early November 1991," Monthly Weather Review, Vol. 138, No. 7, 2010, pp. 2546-2569. http://dx.doi.org/10.1175/2010MWR3280.1

[13] J. Arnoult and F. Roux, "Case Study of a Development African Easterly Wave during NAMMA: An Energetic Point of View," Journal of the Atmospheric Sciences, Vol. 66, No. 10, 2009, pp. 2991-3020. http://dx.doi.org/10.1175/2009JAS3009.1

[14] J. A. Veiga, A. B. Pezza, I. Simmonds and P. L. Silva Dias, "An Analysis of the Environmental Energetics Associated with the Transition of the First South Atlantic Hurricane," Geophysical Research Letters, Vol. 35, No. L15, 2008, Article ID: L15806.

[15] M. A. Wahab, H. A. Basset and A. M. Lasheen, "On the Mechanism of Winter Cyclogenesis in Relation to Vertical Axis Tilt," Meteorology and Atmospheric Physics, Vol. 81, No. 1-2, 2002, pp. 103-127. http://dx.doi.org/10.1007/s007030200033

[16] R. A. Plumb, "A New Look at the Energy Cycle," Journal of the Atmospheric Sciences, Vol. 40, No. 7, 1983, pp. 1669-1688.

http://dx.doi.org/10.1175/1520-0469(1983)040<1669:AN LATE $>2.0 . \mathrm{CO} ; 2$

[17] A. H. Oort, "On Estimates of the Atmospheric Energy Cycle," Monthly Weather Review, Vol. 92, No. 11, 1964, pp. 483-493. http://dx.doi.org/10.1175/1520-0493(1964)092<0483:OE $\underline{\mathrm{OTAE}}>2.3 . \mathrm{CO} ; 2$

[18] A. Wiin-Nielsen, J. A. Brown and M. Drake, "On Atmospheric Energy Conversion between the Zonal Flow and Eddies," Tellus, Vol. 15, No. 3, 1963, pp. 261-279. http://dx.doi.org/10.1111/j.2153-3490.1963.tb01386.x

[19] J. P. Peixoto and A. H. Oort, "The Annual Distribution of Atmospheric Energy on a Planetary Scale," Journal of Geophysical Research, Vol. 79, No. 15, 1974, pp. 21492159. http://dx.doi.org/10.1029/JC079i015p02149

[20] C. A. F. Marques, A. Rocha, J. Corte-Real et al., "Global Atmospheric Energetics from NCEP-Reanalysis 2 and ECMWF-ERA40 Reanalysis," International Journal of Climatology, Vol. 29, No. 2, 2009, pp. 159-174. http://dx.doi.org/10.1002/joc.1704

[21] C. A. F. Marques, A. Rocha and J. Corte-Real, "Global Diagnostic Energetics of Five State-of-Art Climate Models," Climate Dynamics, Vol. 36, No. 10, 2011, pp. 17671794. http://dx.doi.org/10.1007/s00382-010-0828-9

[22] D. Hernández-Deckers and J. S. von-Storch, "The Energetics Response to a Warmer Climate: Relative Contributions from the Transient and Stationary Eddies," Earth System Dynamics, Vol. 2, 2011, pp. 105-120. http://dx.doi.org/10.5194/esd-2-105-2011

[23] S. Murakami, "Atmospheric Local Energetics and Energy Interactions between Mean and Eddy Fields. Part I: Theory," Journal of the Atmospheric Sciences, Vol. 68, No. 4, 2011, pp. 760-768.

\section{http://dx.doi.org/10.1175/2010JAS3664.1}

[24] J. A. Veiga, V. B. Rao and S. H. Franchito, "Heat and Moisture Budgets of the Walker Circulation and Associated Rainfall Anomalies during El Niño Events," International Journal of Climatology, Vol. 25, No. 2, 2005, pp. 193-213. http://dx.doi.org/10.1002/joc. 1115

[25] E. N. Lorenz, "Available Potential Energy and the Maintenance of the General Circulation," Tellus, Vol. 7, 1955, pp. 157-167. http://dx.doi.org/10.1111/j.2153-3490.1955.tb01148.x

[26] J. R. D. Pinto and R. P. Rocha, "The Energy Cycle and Structural Evolution of Cyclones over Southeastern South America in Three Case Studies," Journal of Geophysical Research, Vol. 116, No. D14, 2011. http://dx.doi.org/10.1029/2011JD016217

[27] E. N. Lorenz, "The Nature and Theory of the General Circulation of the Atmosphere," World Meteorological Organization Publications, Geneva, Vol. 218, 1967, 161 p.

[28] H. S. Muench, "On the Dynamics of the Wintertime Stratosphere Circulation," Journal of the Atmospheric Sciences, Vol. 22, No. 4, 1965, pp. 340-360. http://dx.doi.org/10.1175/1520-0469(1965)022<0349:OT DOTW $>2.0 . \mathrm{CO} ; 2$

[29] A. Wiin-Nielsen, J. A. Brown and M. Drake, "On Atmospheric Energy Conversion between the Zonal Flow and Eddies," Tellus, Vol. 15, 1963, pp. 261-279. http://dx.doi.org/10.1111/j.2153-3490.1963.tb01386.x

[30] J. P. Peixoto and A. H. Oort, "Physics of Climate," American Institute of Physics, New York, 1992.

[31] G. A. Vecchi, B. J. Soden, A. T. Wittenberg, et al., "Weakening of the Topical Atmospheric Circulation Due to Anthropogenic Forcing," Nature, Vol. 419, No. 7089, 2006, pp. 73-76. http://dx.doi.org/10.1038/nature04744

[32] G. A. Vecchi and B. J. Soden, "Global Warming and the Weakening of the Tropical Circulation," Journal of Climate, Vol. 20, No. 17, 2007, pp. 4316-4340. http://dx.doi.org/10.1175/JCLI4258.1

[33] T. M. Merlis and T. Schneider, "Changes in Zonal Surface Temperature Gradients and Walker Circulations in a Wide Range of Climates," Journal of Climate, Vol. 24, No. 17, 2011, pp. 4757-4768. http://dx.doi.org/10.1175/2011JCLI4042.1

[34] H. L. Tanaka, N. Ishizaki and A. A. Kitoh, "Trend and Interannual Variability of Walker, Monsoon and Hadley Circulations Defined by Velocity Potential in the Upper Troposphere," Tellus, Vol. 56, 2004, pp. 250-269. http://dx.doi.org/10.1111/j.1600-0870.2004.00049.x

[35] S. B. Power and I. N. Smith, "Weakening of the Walker Circulation and Apparent Dominance of El Niño Both Reach Record Levels, but Has ENSO Really Changed?" Geophysical Research Letters, Vol. 34, No. 18, 2007, in press.

[36] H. Tokinaga, S. P. Xie, C. Deser, et al., "Slowdown of the Walker Circulation Driven by Tropical Indo-Pacific Warming," Nature, Vol. 491, No. 7424, 2012, pp. 439443. http://dx.doi.org/10.1038/nature11576

[37] Q. Meng, M. N. Latif, S. Keenlyside and T. Martin, 
"Twentieth Century Walker Circulation Change: Data Analysis and Model Experiments," Climate Dynamics, Vol. 38, No. 9-10, 2012, pp. 1757-1773. http://dx.doi.org/10.1007/s00382-011-1047-8

[38] S. B. Power and G. Kociuba, "The Impact of Global
Warming on the Southern Oscillation Index," Climate Dynamics, Vol. 37, No. 9-10, 2011, pp. 1745-1754. http://dx.doi.org/10.1007/s00382-010-0951-7

\section{APPENDIX}

\section{Lorenz energetics}

Equations of Lorenz in Spatial Domain

Mathematical expression of components in the energy balance Equations 2(c)-2(b).

The zonal mean of a variable $X$ between longitudes $\lambda_{1}$ and $\lambda_{2}$ is given by

$$
[X]_{\lambda}=\frac{1}{\lambda_{2}-\lambda_{1}} \int_{p_{1}}^{p_{2}} X \mathrm{~d} \lambda
$$

The eddy component of this variable is:

$$
(X)_{\lambda}=X-[X]_{\lambda}
$$

The mean of $X$ over an area bounded by longitudes $\lambda_{1}$ and $\lambda_{2}$ and latitudes $\phi_{1}$ and $\phi_{2}$ is

$$
[X]_{\lambda \phi}=\frac{1}{\lambda_{2}-\lambda_{1}} \frac{1}{\sin \phi_{2}-\sin \phi_{1}} \int_{\phi_{1}}^{\phi_{2}} \int_{\lambda_{1}}^{\lambda_{2}} X \cos \phi \mathrm{d} \lambda \mathrm{d} \phi
$$

Defining the quantity

$$
\left([X]_{\lambda}\right)_{\phi}=[X]_{\lambda}-[X]_{\lambda \phi}
$$

The four energy forms in the SDLEC are

$$
\begin{gathered}
\mathrm{AZ}=\int_{p_{1}}^{p_{2}} \frac{\left[\left([T]_{\lambda}\right)_{\phi}^{2}\right]_{\lambda \phi}}{2[\sigma]_{\lambda \phi} \mathrm{d} p} \mathrm{CE} \int_{p_{1}}^{p_{2}}-\left[(\omega)_{\lambda}(T)_{\lambda}\right]_{\lambda \phi} \frac{R}{g p} \mathrm{~d} p \\
\mathrm{CA}=\int_{p_{1}}^{p_{2}}-\left(\left[\frac{(v)_{\lambda}(T)_{\lambda}}{2[\sigma]_{\lambda \phi} r} \frac{\partial\left([T]_{\lambda}\right)}{\partial \phi}\right]_{\lambda \phi}+\left[\frac{(\omega)_{\lambda}(T)_{\lambda}}{p^{R / c_{p}}} \frac{\partial}{\partial p}\left(\frac{\left([T]_{\lambda}\right)_{\phi} p^{R / c_{p}}}{[\sigma]_{\lambda \phi}}\right)\right]_{\lambda \phi}\right) \mathrm{d} p \\
\mathrm{CK}=\int_{p_{1}}^{p_{2}} \frac{1}{g}\left[(v)_{\lambda}(u)_{\lambda} \frac{\cos \phi}{r} \frac{\partial}{\partial \phi}\left(\frac{\left.[u]_{\lambda}\right)}{\cos \phi}\right]\right]_{\lambda \phi} \mathrm{d} p+\int_{p_{1}}^{p_{2}} \frac{1}{g}\left[\frac{(v)_{\lambda}^{2}}{r} \frac{\partial[v]_{\lambda}}{\partial \phi}\right]_{\lambda \phi} \mathrm{d} p \\
+\int_{p_{1}}^{p_{2}} \frac{1}{g}\left[[v]_{\lambda}(u)_{\lambda}^{2} \frac{\tan \phi}{r}\right]_{\lambda \phi} \mathrm{d} p-\int_{p_{1}}^{p_{2}} \frac{1}{g}\left[(\omega)_{\lambda}(u)_{\lambda} \frac{\partial[u]_{\lambda}}{\partial p}\right]_{\lambda \phi} \mathrm{d} p \\
+\int_{p_{1}}^{p_{2}} \frac{1}{g}\left[(\omega)_{\lambda}(v)_{\lambda} \frac{\partial[v]_{\lambda}}{\partial p}\right]_{\lambda \phi} \mathrm{d} p
\end{gathered}
$$

where $p_{1}$ and $p_{2}$ are, respectively, the upper and lower pressure boundaries, $T$ is the temperature, $g$ the magnitude of the acceleration of gravity, $u$ and $v$ are the eastward and northward components of the wind, respectively, and $\sigma$ is the static stability parameter which is given by

$$
\begin{gathered}
\mathrm{AE}=\int_{p_{1}}^{p_{2}} \frac{\left[(T)_{\lambda}^{2}\right]_{\lambda \phi}}{2[\sigma]_{\lambda \phi}} \mathrm{d} p \\
\mathrm{KZ}=\int_{p_{1}}^{p_{2}} \frac{\left[[u]_{\lambda}^{2}+[v]_{\lambda}^{2}\right]_{\lambda \phi}}{2 g} \mathrm{~d} p \\
\mathrm{KE}=\int_{p_{1}}^{p_{2}} \frac{\left[(u)_{\lambda}^{2}+(v)_{\lambda}^{2}\right]_{\lambda \phi}}{2 g} \mathrm{~d} p
\end{gathered}
$$

$$
\begin{gathered}
{[\sigma]_{\lambda \phi}=\left[\frac{g T}{c_{p}}-\frac{g p}{R} \frac{\partial T}{\partial p}\right]_{\lambda \phi}} \\
\mathrm{CZ}=\int_{p_{1}}^{p_{2}}-\left[\left([\omega]_{\lambda}\right)_{\phi}\left([T]_{\lambda}\right)_{\phi}\right]_{\lambda \phi} \frac{R}{g p} \mathrm{~d} p
\end{gathered}
$$


where $r$ denotes the mean radius of the Earth.

The generation of APE terms and kinetic energy dissipation terms are

$$
\begin{aligned}
& \mathrm{GZ}=\int_{p_{1}}^{p_{2}} \frac{\left[\left([q]_{\lambda}\right)_{\phi}\left([T]_{\lambda}\right)_{\phi}\right]_{\lambda \phi}}{c_{p}[\sigma]_{\lambda \phi}} \mathrm{d} p \\
& \mathrm{BAZ}=c_{1} \int_{p_{1}}^{p_{2}} \int_{\lambda_{1}}^{\lambda_{2}} \frac{1}{2[\sigma]_{\lambda \phi}}\left(2\left([T]_{\lambda}\right)_{\phi}(T)_{\lambda} u+\left([T]_{\lambda}\right)_{\phi}^{2} u\right)_{\lambda_{1}}^{\lambda_{2}} \mathrm{~d} \phi \mathrm{d} p \\
& +c_{2} \int_{p_{1}}^{p_{2}} \frac{1}{2[\sigma]_{\lambda \phi}}\left(2\left[(v)_{\lambda}(T)_{\lambda}\right]_{\lambda}\left([T]_{\lambda}\right)_{\phi} \cos \phi+\left([T]_{\lambda}\right)_{\phi}^{2}[v]_{\lambda} \cos \phi\right)_{\phi_{1}}^{\phi_{2}} \mathrm{~d} p \\
& -\frac{1}{2[\sigma]_{\lambda \phi}}\left(\left[2(\omega)_{\lambda}(T)_{\lambda}\right]_{\lambda}\left([T]_{\lambda}\right)_{\phi}+\left[[\omega]_{\lambda}\left([T]_{\lambda}\right)_{\phi}^{2}\right]_{\lambda \phi}\right)_{p_{1}}^{p_{2}} \\
& \mathrm{BAE}=c_{1} \int_{p_{1}}^{p_{2}} \int_{\phi_{1}}^{\phi_{2}} \frac{1}{2[\sigma]_{\lambda \phi}}\left[u(T)_{\lambda}^{2}\right]_{\lambda_{1}}^{\lambda_{2}} \mathrm{~d} \phi \mathrm{d} p \\
& +c_{2} \int_{p_{1}}^{p_{2}} \frac{1}{2[\sigma]_{\lambda \phi}}\left(\left[(T)_{\lambda}^{2}\right]_{\lambda} \cos \phi\right)_{\phi_{1}}^{\phi_{2}} \mathrm{~d} p-\left(\frac{\left[\omega(T)_{\lambda}^{2}\right]_{\lambda \phi}}{2[\sigma]_{\lambda \sigma}}\right)_{p_{1}}^{p_{2}}
\end{aligned}
$$

where $q$ denotes the diabatic processes associated with

$$
\begin{aligned}
\mathrm{BKZ}= & c_{1} \int_{p_{1}}^{p_{2}} \int_{\phi_{1}}^{\phi_{2}} \frac{1}{2 g}\left(u\left[u^{2}+v^{2}-(u)_{\lambda}^{2}-(v)_{\lambda}^{2}\right]\right)_{\lambda_{1}}^{\lambda_{2}} \mathrm{~d} \phi \mathrm{d} p \\
& +c_{2} \int_{p_{1}}^{p_{2}} \frac{1}{2 g}\left(\left[v \cos \phi\left[u^{2}+v^{2}-(u)_{\lambda}^{2}\right]\right]_{\lambda}\right)_{\phi_{1}}^{\phi_{2}} \mathrm{~d} p \\
& -\left(\frac{1}{2 g}\left[\omega\left[u^{2}+v^{2}-(u)_{\lambda}^{2}-(v)_{\lambda}^{2}\right]\right]_{\lambda \phi}\right)_{p_{1}}^{p_{2}} \\
\mathrm{BKE}= & c_{1} \int_{p_{1}}^{p_{2}} \int_{\phi_{1}}^{\phi_{2}} \frac{1}{2 g}\left(u\left[(u)_{\lambda}^{2}+(v)_{\lambda}^{2}\right]\right)_{\lambda_{1}}^{\lambda_{2}} \mathrm{~d} \phi \mathrm{d} p \\
& +c_{2} \int_{p_{1}}^{p_{2}} \frac{1}{2 g}\left(\left[v \cos \phi\left[(u)_{\lambda}^{2}+\left((v)_{\lambda}^{2}\right)\right]\right]_{\lambda}\right)_{\phi_{1}}^{\phi_{2}} \mathrm{~d} p \\
& -\left(\frac{1}{2 g}\left[\omega\left[(u)_{\lambda}^{2}+(v)_{\lambda}^{2}\right]\right]_{\lambda \phi}\right)_{p_{1}}^{p_{2}}
\end{aligned}
$$

where

$$
\begin{gathered}
c_{1}=-\left[r\left(\lambda_{2}-\lambda_{1}\right)\left(\sin \phi_{2}-\phi_{1}\right)\right]^{-1} \\
c_{2}=-\left[r\left(\sin \phi_{2}-\phi_{1}\right)\right]^{-1}
\end{gathered}
$$

Finally the integrals for $\mathrm{B} \Phi \mathrm{Z}$ and $\mathrm{B} \Phi \mathrm{E}$ are

$$
\begin{aligned}
\mathrm{B} \Phi \mathrm{Z}= & c_{1} \int_{p_{1}}^{p_{2}} \int_{\phi_{1}}^{\phi_{2}} \frac{1}{g}\left([v]_{\lambda}\left([\Phi]_{\lambda}\right)_{\phi}\right)_{\lambda_{1}}^{\lambda_{2}} \mathrm{~d} \phi \mathrm{d} p \\
& +c_{2} \int_{p_{1}}^{p_{2}} \frac{1}{g}\left(\cos \phi[v]_{\lambda}\left([\Phi]_{\lambda}\right)_{\phi}\right)_{\phi_{1}}^{\phi_{2}} \mathrm{~d} p \\
& -\frac{1}{g}\left(\left[\left([\omega]_{\lambda}\right)_{\phi}\left([\Phi]_{\lambda}\right)_{\phi}\right]_{\lambda \phi}\right)_{p_{1}}^{p_{2}} \\
\mathrm{~B} \Phi \mathrm{E}= & c_{1} \int_{p_{1}}^{p_{2}} \int_{\phi_{1}}^{\phi_{2}} \frac{1}{g}\left((u)_{\lambda}(\Phi)_{\lambda}\right)_{\lambda_{1}}^{\lambda_{2}} \mathrm{~d} \phi \mathrm{d} p \\
& +c_{2} \int_{p_{1}}^{p_{2}} \frac{1}{g}\left(\left[(v)_{\lambda}(\Phi)_{\lambda}\right] \cos \phi\right)_{\phi_{1}}^{\phi_{2}} \\
& -\frac{1}{g}\left(\left[(\omega)_{\lambda}(\Phi)_{\lambda}\right]_{\lambda \phi}\right)_{p_{1}}^{p_{2}}
\end{aligned}
$$

where $\Phi(=g z)$ is the geopotential. 